\title{
Pump the brakes: Getting ahead of ourselves with concomitant tricuspid annuloplasty?
}

\author{
David D. Yuh, MD, FACS, FACC
}

From the Department of Surgery, Stamford Hospital, Stamford, Conn.

Disclosures: Author has nothing to disclose with regard to commercial support.

Received for publication March 13, 2018; accepted for publication March 19, 2018; available ahead of print April $24,2018$.

Address for reprints: David D. Yuh, MD, FACS, FACC, Department of Surgery, Stamford Hospital, Stamford, CT 06902 (E-mail: DYuh@stamhealth.org).

J Thorac Cardiovasc Surg 2018;156:1062-3

$0022-5223 / \$ 36.00$

Copyright (c) 2018 by The American Association for Thoracic Surgery

https://doi.org/10.1016/j.jtcvs.2018.03.062

The study by Sakata and colleagues ${ }^{1}$ adds to the growing body of evidence supporting the performance of tricuspid annuloplasty for functional tricuspid regurgitation in conjunction with left-sided valve surgery. The significance of this work lies in providing kernels of data that suggest even more aggressive surgical treatment of functional tricuspid regurgitation concomitantly with left-sided valve surgery than outlined in the most recent 2014 American Heart Association/American College of Cardiology consensus clinical guidelines. ${ }^{2}$ The authors showed that patients undergoing left-sided valve surgery without concomitant tricuspid annuloplasty experienced right ventricular remodeling (ie, increased diastolic diameter) after only 1 year, whereas those who did undergo tricuspid repair demonstrated reverse right ventricular remodeling over the same time interval. Significantly, the clear majority of these patients had only mild tricuspid insufficiency and a mean tricuspid annular diameter significantly less than the $40 \mathrm{~mm}$ threshold for concomitant tricuspid repair specified in current guidelines; this was demonstrated both before and after propensity score-matching analyses. One can infer that these data support concomitant correction of even mild tricuspid regurgitation regardless of the type of left-sided valvular disease and degree of annular dilatation.

However, one must be cautious in extrapolating the results from this heterogeneous and relatively small patient cohort to suggest that mild tricuspid regurgitation without significant annular dilatation should be routinely addressed in patients undergoing degenerative mitral surgery, given that longer-term evidence of right ventricular remodeling supports concomitant repair of moderate to severe tricuspid regurgitation or annular dilatation. ${ }^{3,4}$ Although some studies, including this one, suggest that tricuspid repair adds little to the operative risk of left-sided valve surgery, Jouan and colleagues ${ }^{5}$ recently reported a significantly higher incidence of high-grade heart block lasting more than 3 days postoperatively among patients undergoing tricuspid annuloplasty in conjunction with mitral valve surgery $(41.2 \%$ vs $14.5 \%)$ and a significantly lower freedom from permanent pacemaker implantation at 3 years

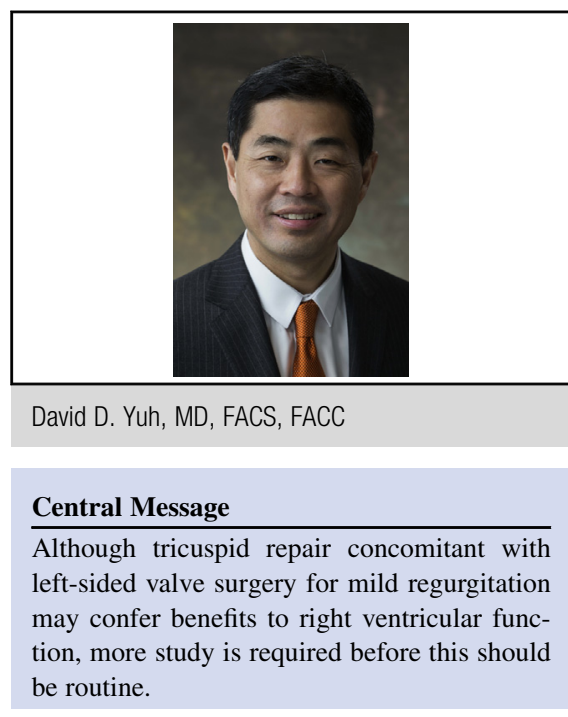

See Article page 1050.

(94.1\% vs $99 \%)$; tricuspid ring annuloplasty was found to be an independent predictor of heart block. ${ }^{5}$ Moreover, mild functional tricuspid regurgitation without significant annular dilatation can be effectively treated with (1) leftsided valve surgery alone in patients with pulmonary arterial hypertension stemming from left-sided valve lesions or, as the authors note, (2) standard medical therapies (eg, diuretics). The challenges of assessing the relative contributions of fixed and reversible pulmonary hypertension on mild to moderate tricuspid regurgitation make it difficult to apply these guidelines across broad populations.

Finally, it is important to note that tricuspid annuloplasty did not result in significant improvement of right ventricular function after 1 year in this study. This is consistent with the findings of Chikwe and colleagues, ${ }^{3}$ who noted an initial deterioration in right ventricular function from baseline among patients undergoing concomitant mitral and tricuspid repair over the first year, followed by progressive recovery and improvement compared with baseline over the ensuing 4 years. Naturally, it is important to see eventual improvement of right ventricular function among the patients in this or future studies of this issue to substantiate the case for more aggressive surgical correction of tricuspid insufficiency.

\section{References}

1. Sakata T, Mogi K, Sakurai M, Nomura A, Fujii M, Kaneyuki D, et al. Effect of tricuspid annuloplasty concomitant with left heart surgery on right heart geometry and function. J Thorac Cardiovasc Surg. 2018;156:1050-61. 
2. Nishimura RA, Otto CM, Bonow RO, Carabello BA, Erwin JP III, Guyton RA, et al. 2014 AHA/ACC guideline for the management of patients with valvular heart disease: a report of the American College of Cardiology/American Heart Association Task Force on Practice Guidelines. J Thorac Cardiovasc Surg. 2014;148:e1-132.

3. Chikwe J, Itagaki S, Anyanwu A, Adams DH. Impact of concomitant tricuspid annuloplasty on tricuspid regurgitation, right ventricular function, and pulmonary artery hypertension after repair of mitral valve prolapse. JAm Coll Cardiol. 2015;65:1931-8.
4. Filsoufi F, Chikwe J, Carpentier A. Rationale for remodeling annuloplasty to address functional tricuspid regurgitation during left-sided valve surgery. Eur J Cardiothorac Surg. 2015;47:1-3.

5. Jouan J, Mele A, Florens E, Chatellier G, Carpentier A, Achouh P, et al. Conduction disorders after tricuspid annuloplasty with mitral valve surgery: implications for earlier tricuspid intervention. J Thorac Cardiovasc Surg. 2016;151 99-103. 